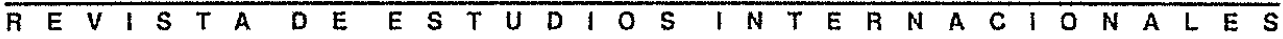

\section{Estados Unidos y la Unión Europea en el siglo XXI. Fundamentos y alcances de una unidad y diversidad}

José A. Morandé Lavín

La relación entre Estados Unidos y Europa es abordada en este artículo a partir de la creación y génesis de la llamada Alianza Atlántica o Comunidad Transatlántica en el contexto de la post Guerra Mundial, de mediados del siglo XX hasta nuestros dias. Las expectativas y desafios que plantean las transformaciones del sistema internacional a esta asociación estratégica, tanto desde el término de la Guerra Fría como después de la entrada en escena del terrorismo transnacional son analizados y comentados desde la óptica de la política exterior de Estados Unidos y de su impacto en las visiones y conductas europeas. Cuatro son las preguntas orientadoras de este ensay'o, que apuntan a una observación crítica de la relación atlántica y que intentan explicar las aproximaciones y distanciamientos de dicha sociedad en un mundo en cambio, con renovados roles internacionales de sus actores más relevantes, como también de las potencialidades para la permanencia y consolidación de esta experiencia histórica. En otras palabras, se pretende responder, en forma muly preliminar y' con algunos ejemplos ilustradores de la realidad transatlántica contemporánea, las siguientes interrogantes: ¿cuáles son los rasgos y fundamentos que definen y' justifican la interacción y' la asociación entre Estados Unidos y Europa?, ¿en qué consisten las orientaciones y pautas de acción de la política exterior de Estados Unidos?, ¿a qué responden las fricciones y divergencias en la Alianza Atlántica y' cuáles son las esferas de cooperación entre sus miembros? Finalmente, jes posible la diversidad en la unidad de la comunidad atlántica? 


\section{INTRODUCCIÓN}

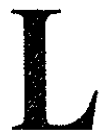

a actual vinculación entre Estados Unidos y la Unión Europea se remonta a la creación de la llamada Comunidad Transatlántica al término de 1a II Guerra Mundial. La existencia de poco más de medio siglo de esta asociación transatlántica ha estado sujeta al desarrollo y a las transformaciones experimentadas por el sistema internacional, desde la bipolaridad de la Guerra Fría hasta los rasgos unilaterales que representa actualmente la hegemonía de Estados Unidos, sin perjuicio de haber intervenido también activamente como actor determinante en materias gravitantes de la política mundial durante todo este período.

En otras palabras, la Alianza Atlántica nace en el contexto internacional de la confrontación Este-Oeste en el marco de la estrategia occidental de la contención de la amenaza que representaba la expansión de la Unión Soviética en Europa y la difusión ideológica del comunismo en el mundo. De esta manera, la asociación transatlántica representa una activa cooperación y una interrelación del mundo occidental en variadas materias, desde las políticas y de seguridad hasta las económicas y culturales. Para ello se crearon instituciones como la OTAN, el Fondo Monetario Internacional, el Banco Mundial, la OCDE y la propia Comunidad Europea. Todas ellas generalmente han cumplido sus funciones bajo el ordenamiento y el liderazgo de los Estados Unidos.

Más tarde, sin embargo, los aliados occidentales fueron testigos y actores del fin del sistema internacional para el cual fueron preparados. En efecto, desde la desaparición de la Unión Soviética, la asociación transatlántica ha debido enfrentar nuevas expectativas y desafíos en un escenario global diferente del de la Guerra Fría, que a comienzos de la década de 1990 el ex presidente de Estados Unidos, George Bush, denominó triunfalmente como el nacimiento de un Nuevo Orden Internacional. Este ordenamiento internacional apostó a la expansión de la democracia y de la economía de mercado a nivel global y regional conforme a la nueva estrategia estadounidense del "Enlargement", acuñada por el Asistente de Seguridad del presidente Clinton, Anthony Lake. En este marco, continúa en su plan de integración económica y política, y ahora militar con la expansión de la OTAN, bajo la mirada atenta de Estados Unidos.

\section{Los aliados occidentales fueron testigos y autores del fin del sistema internacional para el cual fueron preparados.}

La euforia inicial del liberalismo y del liderazgo estadounidense y occidental a fines del siglo recién pasado tendrá como contrapartida el surgimiento, a comienzos del siglo XXI, de una amenaza diferente y radical, el terrorismo transnacional. En efecto, la materialización de acciones terroristas por parte de redes transnacionales en varios países simultáneamente y cuya entrada en escena fueron los acontecimientos dramáticos del 11 de septiembre 
de 2001 en Estados Unidos, dieron comienzo a una era distinta y a un nuevo escenario en la política mundial. De esta manera, como reacción a dicha amenaza y a partir de esa fecha, el gobierno estadounidense diseña y aplica una estrategia antiterrorista unilateral de alcance mundial. Sin perjuicio de su reacción inicial contra el terrorismo, esta estrategia representa una visión más amplia sobre la forma de ejercer el poder y de organizar el orden mundial, para lo cual no siempre se ceñirá estrictamente a una acción conjunta con sus socios, ni obedecerá a las reglas e instituciones globales ${ }^{1}$. Más específicamente, ella corresponde a lo que actualmente se identifica como estrategia de seguridad global de la prevención, que se sustenta en un internacionalismo inconfundiblemente norteamericano y al mismo tiempo refleja la unión de los valores e intereses nacionales estadounidenses.

\section{La estrategia antiterrorista estadounidense representa una visión amplia sobre la forma de organizar el orden mundial.}

Reafirmando el nuevo sello de esta política y apelando a la tradicional alianza con sus socios europeos, el Presidente George W. Bush se dirigió a los medios militares norteamericanos en junio de 2002, anticipando sus convicciones respecto de la amenaza constituida por Irak y la posterior intervención en ese país, al señalar:

"No podemos depender solo de la contención y la disuasión para tratar con países que poseen armas de destrucción masiva y que tienen un historial de agresiones y terrorismo. Es importante que Estados Unidos y Europa lleguen a un acuerdo sobre cómo hacer frente a la amenaza iraqui"."

Los acontecimientos que siguieron a esta declaración en 2003, particularmente la intervención militar estadounidense en Irak y el debate previo en el Consejo de Seguridad de las Naciones Unidas, no solo confirmaron la voluntad unilateral de Estados Unidos, sino que significaron un quiebre político importante en la alianza europea, en particular con sus aliados Alemania y Francia. Dicho de otra manera, la actual hegemonía norteamericana y su estrategia de acción unilateral preventiva ha generado nuevos roces en los países de la Alianza Atlántica, poniendo al mismo tiempo de manifiesto los desencuentros y diferencias entre sus miembros, particularmente en el campo de la seguridad y la defensa.

Además, no obstante las tendencias más recientes del gobierno de Bush, particularmente a partir de su segunda administración, de complementar y vestir a su política exterior con los aspectos tradicionales de valores democráticos, el uso rei-

1 Ikenberry, G. John, "La ambición imperial de Estados Unidos", en Foreign Affairs en Español, Vol. 2, No 3, Otoño-Invierno 2002, p. 8.

2 Haass, Richard, "Las relaciones transatlánticas en el nuevo orden de seguridad", en Política Exterior, $N^{\circ} 89$, septiembre/octubre de 2002 , p. 45. 
terado y unilateral de la fuerza o "hard power" por parte del gobierno estadounidense en la arena internacional, en especial en el caso emblemático de la intervención militar en Irak, han contribuido a un creciente sentimiento contra Estados Unidos en el mundo ${ }^{3}$. Este sentimiento, sin embargo, no es nuevo global ni regionalmente. En el caso europeo, las críticas van desde el doble estándar de la política exterior estadounidense al no cumplir compromisos internacionales contraídos frente a situaciones que afectan a la humanidad hasta diferencias respecto de la secularización social o a la aplicación de valores universales supuestamente compartidos.

\section{El uso del hard power ha contribuido} a un creciente sentimiento negativo frente a Estados Unidos.

En función de lo anterior y atendiendo al tema descle la óptica de los Estados Unidos, es posible formular algunas preguntas orientadoras para esta reflexión: 1. ¿Cuáles son los rasgos y fundamentos que definen y justifican la interacción y asociación entre Estados Unidos y Europa?; 2. ¿En qué consisten las orientaciones y pautas de acción de la política exterior de Estados Unidos?; 3. ¿A qué responden las fricciones y divergencias en la Alianza Atlántica y cuáles son las esferas de cooperación entre sus miembros? y 4. ¿Es posible la diversidad en la unidad de la comunidad atlántica?

\section{LA HEGEMONÍA GLOBAL DE LOS ESTADOS UNIDOS Y LA INTERACCIÓN ATLÁNTICA}

La continuidad del poderío norteamericano a escala global supera el medio siglo. En efecto, después de la Segunda Guerra Mundial, Estados Unidos asume un papel de liderazgo en el mundo y al mismo tiempo incrementa y consolida su hegemonía militar, económica y cultural indiscutida en el concierto internacional. En la actualidad, a los inicios del siglo XXI, constatamos su carácter de potencia mundial de alcance inigualado en el ámbito militar, liderando la globalización económica internacional, a pesar de la competencia de algunas economías industrializadas. En el plano tecnológico, la nación norteamericana mantiene una posición superior en la jerarquía global, particularmente en los sectores de punta en materia de innovación. La influencia cultural norteamericana, por su parte, disfruta de sin rival atractivo, especialmente entre las nuevas generaciones de la población mundial.

En su último libro, Henry Kissinger sostiene que los Estados Unidos están alcanzando una preeminencia sin rival, superior incluso a aquella de los imperios del pasado. Esta superioridad se expresa "desde las armas a la empresa, desde la

3 Nye Jr., Joseph S., “The Decline of America's Soft Power. Why Washington Should Worry?", en Foreign Affairs, Vol. 83, N³, May/June 2004, pp. 16-18. 
ciencia a la tecnología, desde la educación superior a la cultura popular, América ejerce un ascendiente sin paralelo alrededor del globo"4. En similares términos se expresa más tarde Samuel P. Huntington, al señalar que tras el fin de la Unión Soviética, Estados Unidos se ha transformado en la única superpotencia, con virtual liderazgo en cada uno de los aspectos del poder global. Sin embargo, el mismo autor muestra especial preocupación por las nuevas amenazas a la seguridad norteamericana y por la pérdida de la impresión de invulnerabilidad de la población estadounidense frente a los ataques externos especialmente después de la trágica experiencia del 11 de septiembre de $2001^{5}$.

\section{El dinamismo del sistema internacional admite la participación de actores que no facilitan la conducta exterior estadounidense.}

No obstante las características hegemónicas de Estados Unidos a nivel global, la vulnerabilidad de su poder se expresa no sólo en los temores y sentimientos de la nación norteamericana en el ámbito de su seguridad, ya que el actual dinamismo del sistema internacional admite espacios de participación a los distintos actores de la política mundial que no necesariamente facilitan el libre accionar de la conducta exterior norteamericana. En efecto, la gobernabilidad del mundo de hoy exige la estructuración de mecanismos colectivos y la participación de variados actores en diferentes niveles, más allá de la dimensión tradicional de seguridad, lo que permite identificar competencias en los ámbitos de la economía política internacional y de la llamada sociedad civil internacional. Al respecto, es ilustrativo el modelo tridimensional de "tableros de ajedrez" de la política mundial y del papel global de Estados Unidos que nos ofrece Joseph S. Nyé.

En primer término, este autor señala el "tablero superior", de carácter unipolar y en el que opera el poder militar. En este ámbito, Estados Unidos es el único país que cuenta con fuerzas aéreas, navales y terrestres ultramodernas y aptas para un despliegue mundial. En seguida, el "tablero intermedio", en gran medida multipolar, en el que opera el poder económico interestatal. Este tiende a compartirse entre las economías de Estados Unidos, Europa, Japón y China, por lo cual existe un contrapeso al poder norteamericano. Por último, el "tablero inferior" considera las relaciones transnacionales que cruzan las fronteras y quedan fuera del control de los gobiernos. La sociedad civil se expresa en esta dimensión, con la participación activa de actores trasnacionales de diver-

4 Kissinger, Henry, Does America Need a Foreign Policy? Toward a Dilomacy for the 21 st Century. Nueva York, Simon \& Schuster, 2004, p. 17.

5 Huntington, Samuel P., Who are we? The Challenges to America's National Identity, Nueva York, Simon \& Schusier, 2004, p. 336.

6 Nye Jr., Joseph S., Soft Power: The Means to Success in World Politics, Nueva York, Public Affairs, 2004, pp. 4-5. 
sa naturaleza. El poder se encuentra más disperso y constituye un escenario de reales desafíos a los poderes tradicionales, particularmente a los alcances y limitaciones del poder militar estadounidense. Por lo tanto, para obtener resultados favorables en este tablero transnacional, Estados Unidos requiere utilizar sus recursos de "poder blando".

\section{Estados Unidos es el único país que cuenta con fuerzas aptas para un despliegue mundial.}

Europa también es fuerte competidor de Estados Unidos en materia de recursos de "poder blando". En efecto, diferentes expresiones de la cultura europea, desde el arte a la alimentación, han servido tradicionalmente a los países del continente como atractivos culturales a nivel global y regional. Desde el punto de vista político y de identidad histórica, el fin de la Guerra Fría puso en evidencia el deseo y objetivo de muchos países de Europa del Este de integrarse a la Unión Europea. De ahí que las declaraciones y esfuerzos oportunistas por distinguir el continente dividiéndolo entre la "vieja y la nueva Europa", del Secretario de Defensa de Estados Unidos, Donald Rumsfeld, durante la Guerra de Irak en 2003, generaron encontradas reacciones por parte de los propios líderes europeos y el rechazo amplio de su población.

Pese a la competencia que pueda existir en este nivel de poder entre Estados Unidos y Europa, existe también un amplio espacio de colaboración. En otras palabras, el poder blando admite coincidencias profundas en la Alianza Atlántica desde el punto de vista de la promoción de la democracia y de los derechos humanos. En este sentido, el compartir este clase de valores permite aunar esfuerzos en la lucha contra el terrorismo internacional, en especial cuando éste se manifiesta y justifica abiertamente contra los valores de Occidente. La utilización de este poder internacional conjunto de que dispone la Alianza Atlántica dependerá de la voluntad política de Estados Unidos de compartir esfuerzos y sumar acciones multilaterales en diferentes frentes de la política mundial.

Desde un punto de vista de la tradición intelectual acerca de los fundamentos de la inserción norteamericana en la política mundial actual, ésta puede identificarse a partir de la conjugación, con diferentes énfasis, de las estrategias realista y liberal. La primera se ha sustentado en una racionalidad política mediante la cual ha logrado compromisos importantes de seguridad a escala global. La segunda, liberal, apuesta a la creación de una comunidad internacional que reconoce la formación de una coalición global creciente de Estados democráticos, vinculados por los mercado y por instituciones internacionales de seguridad. Así, entonces, a partir del término de la Segunda Guerra Mundial, el orden internacional se estructuró sobre la base de un compromiso histórico en virtud del cual Estados Unidos proporciona a sus socios europeos y asiáticos protección en el campo de la seguridad y acceso al mercado, tecnología y suministros estadounidenses, en el 
marco de una economía abierta al mundo. A su vez, dichos países se comprometen, como socios confiables, a proporcionar a Estados Unidos respaldo diplomático, económico y estratégico respecto de su papel de líder del mundo occidental de posguerra ${ }^{7}$. Estas visiones y compromisos han tenido una continuidad aún manifiesta en el mundo de la post Guerra Fría, no obstante las expresiones de unilateralismo y hegemonía de la reciente administración de George W. Bush.

El orden internacional se estructuró a partir del compromiso de proporcionar seguridad y acceso al mercado, tecnología y suministros estadounidenses.

Una reflexión acerca del pensamiento realista y su aplicación al nuevo ordenamiento global de nuestros días es la que ofrece Palacio de Oteyza, a partir de cuatro imágenes internacionales prevalecientes en el escenario mundial ${ }^{8}$.

- Imagen geoeconómica: La competencia militar se traslada principalmente al ámbito de la competencia económica entre los principales países industriales. Equivale al tablero intermedio de Nye y es el contexto actual de la globalización, en que los Estados compiten por mercados, empleo, dominio de la tecnología y con niveles dispares de integración, según las áreas, los Estados y las regiones. Regionalización de la economía mundial en torno a la tríada, en la cual se concentran los flujos de comercio y capital del PIB mundial (bloques del NAFTA, la UE y asiático).

- Imagen multipolar: Coincide en parte con la anterior, y representa el retorno a un sistema multipolar, pero con un peso decisivo del poder militar. Ausencia de "hegemon" y presencia de alianza flexibles entre las grandes potencias. Este sería el estado natural del orden internacional para los realistas en el campo internacional.

- Imagen unipolar: Representa una estructura de poder del orden internacional en la que las enormes capacidades de una superpotencia hacen imposible que las demás grandes potencias puedan contrarrestarla. Equivale al «tablero superior» de Nye y Estados Unidos emerge en el escenario internacional de fines del siglo XX y comienzos del actual, como único garante del orden internacional.

- Imagen imperial: Escenario postseptiembre de 2001, en que la existencia de una sola gran potencia reúne en sí tantas capacidades como para formar un imperio global, rompiendo el mecanismo de equilibrio de poder. Es el giro de la política exterior norteamericana de George W. Bush, que pasa de una agenda económica a otra de seguridad y del multilateralismo al unilateralismo como accio-

7 Ikenberry, G. John, op. cit., pp. 7-8.

\& Palacio de Oteyza, Vicente, "La imagen imperial del nuevo orden internacional: ¿Es esto Realismo Político?", en Revisıa CIDOB de Àfers Internacional, diciembre 2003/enero 2004, pp. 10-18. 
nar predominante en su conducta externa. Su actual estrategia de "estado de guerra" o "war time" contra el terrorismo global implica una hegemonía estadounidense desde el momento que lo obliga a una presencia en todo el mundo.

\section{La preeminencia de una imagen imperial acarrea costos enormes a la potencia hegemónica.}

La preeminencia de una imagen imperial en el mundo post-septiembre de 2001, junto con socavar los acuerdos multilaterales, dañar la infraestructura internacional y minar el espíritu de cooperación entre los Estados, acarrea costos enormes a la potencia hegemónica, muy difíciles de sostener a largo plazo. Es más, el mantenimiento de la paz y la construcción de Estados e instituciones democráticas que persigue el nuevo papel imperial de Estados Unidos requiere necesariamente la formación de coaliciones de países y la cooperación multilateral. En otras palabras y conforme a la agenda antiterrorista estadounidense, dicha potencia necesita la cooperación de los países europeos y asiáticos, tanto en materia de inteligencia, como en el cumplimiento de la ley y el apoyo logístico.

\section{ORIENTACIONES Y PAUTAS \\ DE ACCIÓN DE LA POLÍTICA \\ EXTERIOR ESTADOUNIDENSE}

Si miramos el pasado histórico de la política exterior estadounidense desde sus inicios como Estado-nación hasta nuestros días, es posible constatar una tendencia secular que fluctúa entre dos orientaciones básicas: la tendencia al aislacionismo y la orientación al intemacionalismo 9 .

En la tradición aislacionista, representada desde sus orígenes por líderes como George Washington, el interés nacional está mejor resguardado mediante un distanciamiento del mundo, o en todo caso un acercamiento discreto. Algunas de las expresiones de este aislacionismo fueron la doctrina Monroe en el continente americano, la decisión del Congreso de que la adhesión a la Liga de las Naciones, la legislación sobre neutralidad de los años treinta del siglo pasado y, en cierta medida, el temor a "futuros Vietnam".

Por su parte, la perspectiva internacionalista ve la protección y promoción de los intereses nacionales norteamericanos en el marco de una política exterior activista. En otras palabras, los Estados Unidos no pueden escapar del mundo, ya que los acontecimientos del exterior se relacionan inevitablemente con los intereses estadounidenses y cualquier política que no reconozca esta realidad está condenada al fracaso. Numerosos ejemplos pueden ilustrar esta tendencia, a saber, la membresía y la participación en las Na-

9 Hastedt, Glen P., American Foreign Policy. Past, Present, Future, Nueva Jersey, Prentice Hall, 2003, pp. 32-34. 
ciones Unidas, la OTAN, el Plan Marshall, la Alianza para el Progreso, las acciones encubiertas en el exterior (ClA), el acuerdo sobre los derechos humanos, de Helsinki, y la intervención norteamericana en Corea y Vietnam, entre otros.

\section{El interés nacional se resguarda mejor mediante el distanciamiento del mundo.}

Ambas tradiciones se unen por la convicción de su excepcionalidad y destino manifiesto en cuanto a que hay que proteger las instituciones e ideales norteamericanos. Aislándose de o interviniendo en la política mundial, los asuntos internacionales adquieren importancia o irrelevancia según cómo afecten los ideales y la experiencia histórica estadounidenses.

En cuanto a las pautas cle acción de la política exterior norteamericana, según Hastedt ${ }^{10}$ pueden identificarse tres grandes modelos:

- Unilateralismo: Esto es, predisposición a actuar individualmente en el tratamiento de los temas internacionales. El unilateralismo no establece un curso específico de acción. De esta forma, el aislacionismo, la neutralidad, el activismo y el intervensionismo son todos compatibles con su orientación básica en la política mundial. La forma más conocida de expresión unilateral de Estados Unidos y que se relaciona en forma directa con la política hemisférica, es la llamada doctri- na Monroe, con el Corolario de 1904, del presidente Theodore Roosevelt, en virtud del cual Estados Unidos se autoproclama policía del hemisferio occidental. Expresiones más globales y recientes de este unilateralismo las encontramos en el rechazo al Protocolo de Kyoto sobre el cambio climático y la intervención en Irak por la actual administración estadounidense.

- Pragmatismo moral: Se refiere al doble sentido que los norteamericanos dan a la moralidad en su política exterior. En primer lugar, que la conducta del Estado puede ser juzgada de acuerdo con criterios morales. Por cierto que si la conducta de un Estado no reúne los requisitos de moralidad conforme al estandar estadounidense, hay derecho a juzgar o intervenir. En segundo término, la moralidad norteamericana provee el patrón universal para elaborar juicios y catalogar la acción estatal en las políticas públicas. Un ejemplo actual: la justificación para luchar contra Saddam Hussein y derrocarlo.

- Legalismo: Se sustenta en una visión liberal mediante la cual puede operar con criterios racionales para evitar la guerra y propender a la solución pacifica de las controversias. Para ello aboga por la creación de un sistema global de instituciones y reglas (regímenes internacionales) que permitan a los Estados resolver sus disputas y evitar las guerras. Algunos ejemplos históricos que ilustran esta tradición de la política exterior son la activa participación estadounidense en la creación y desarrollo de instituciones como la

10 Hastedt, Glen P., op. cit., pp. 36-41. 
Liga de las Naciones, las Naciones Unidas, el Banco Mundial, el FMI, el GATT y la OMC. La legitimación de muchas conductas externas de Estados Unidos tienen su razón de ser en este legalismo, que algunos identifican con la tendencia "wilsoniana".

\section{La estrategia de seguridad nacional refleja los valores y los intereses nacionales tradicionales.}

Los cambios operados en la política exterior norteamericana después del 11 de septiembre de 2001 ponen en evidencia algunas de estas orientaciones y pautas de acción tradicionales de la conducta internacional de Estados Unidos. En efecto, su política exterior entra en un nuevo estadio, bajo una estrategia de seguridad nacional de reafirmación hegemónica a nivel global. Esta se basará en un internacionalismo inconfundiblemente norteamericano, que refleja los valores y los intereses nacionales tradicionales. Es decir, junto con reiterar su conocida autoproclamación como portavoz mundial de la libertad y de la dignidad humana, el gobierno de George W. Bush proclama la guerra total contra el terrorismo, su erradicación de raíz, invocando como justificación y legitimación de la nueva política el uso de la fuerza preventiva en el marco de la autodefensa.

Lo anterior significa también un Ilamado a todas las "naciones civilizadas" a sumarse a la lucha contra el terrorismo, asumiendo el costo político del rechazo estadounidense de aquellos países que no se comprometan activamente en esta "cruzada" contra los grupos terroristas y "rogue states". Una opción estratégica, por lo tanto, es el mantenimiento de un mundo unipolar, en el cual Estados Unidos no tiene competidor, ni permite una fuerza que amague su hegemonía. Por 10 tanto, los Estados Unidos deberán estar preparados para actuar en cualquier lugar y en cualquier momento $-y$ en forma preventiva-contra la amenaza terrorista. Los Estados que sean incapaces de administrar la lucha contra este flagelo transnacional perderán su soberanía ${ }^{11}$.

\section{FRICCIONES Y DIVERGENCIAS} en la Alianza Atlántica.

Sin perjuicio de reconocer la persistencia y los logros alcanzados por esta asociación estratégica y cultural a lo largo de las últimas décadas, es preciso despejar los voluntarismos que tienden a privilegiar visiones distantes de la propia realidad, consistentes ya sea en exagerar el optimismo o bien mirar con pesimismo lo que se considera el fracaso total de una experiencia histórica como la que nos ocupa.

Al respecto, el historiador e internacionalista Stanley Hoffman afirma, en un artículo sobre las relaciones norteamericano-europeas recientes, que la Comunidad Atlántica siempre descansó en dos grandes mitos:

1 Ikenberry, John G., "America's Imperial Ambition", en Foreign Affaire, Vol. 81, № 5, sept/oct, 2002, pp. 44-60. 
a. Uno, la ausencia de conflicto entre la Comunidad Atlántica y la integración europea. Este mito ayudó a contener las ambiciones gaullistas de una Europa autónomamente más europea y a asegurar a los aliancistas de ambos lados del Atlántico que la integración europea podría ser vista como subproducto de la Comunidad Atlántica.

b. El segundo mito fue que para los Estados Unidos, Europa continuó siendo el teatro diplomático y estratégico más importante, al que estuvo ligado no solo por intereses vitales económicos y de seguridad, sino también por una cultura y valores comunes ${ }^{12}$.

Para los más pesimistas y críticos de la alianza, el resultado de la intervención en Irak constituye un estudio de caso de esta vinculación atlántica ${ }^{13}$. Si se parte de la base de que no puede mantenerse por muchos años una relación de tirantez, la salida a la crisis de Irak puede dar vuelta este escenario negativo en la medida en que se adopte una política mutuamente complementaria y de apoyo a la reconstrucción del país. Al mismo tiempo, la estabilización y la reforma del Medio Oriente puede solidificar la relación vacilante, ya que si Estados Unidos opta por ir solo, camina directo al precipicio. Sin embargo, en ambas situaciones internacionales, las actuales señales y los gestos de construcción y gestión de una salida pacífica multilateral que está promoviendo la segunda administración de George W. Bush con los socios europeos tradicionales y con Rusia, apuntarían hacia un escenario de cooperación y de esfuerzos más compartidos en el manejo de la crisis.

\section{El escenario negativo creado por la crisis de Irak puede darse vuelta mediante una política mutuamente complementaria.}

Es cierto también que para los críticos de la relación atlántica, la actual coyuntura internacional no refleja por primera vez la existencia de tensiones en la relación bilateral. Sin embargo, hay razones para pensar que los nuevos desafíos que confrontan ambos actores son cualitativamente diferentes de los del pasado, particularmente en el marco de los retos y oportunidades que ofrece la globalización de la economía política internacional. En este sentido, resultan elocuentes la reflexión y los antecedentes históricos que presenta Steinberg sobre la materia ${ }^{14}$ :

- En primer término, el eje trasatlántico fue el corazón de la política mundial y de las relaciones económicas en el ámbito de una competencia estratégica entre la Unión Soviética y Occidente, particularmente desde el término de la II Guerra

12 Hoffman, Stanley, "US-European Relations", en International Affairs, Vol. 79, No 5, October 2003, p. 1030.

13 Daalder, Ivo H., "The End of Allanticism", en Survival, The IISS Quarterly, Vol. 45, № 2, Summer 2003, pp. 148-149.

14 Ver Steinberger, James B., "An Elective Partnership. Salvaging Transatlantic Relations", en Survival, The IISS Quarterly, Vol. 45, N², Summer 2003, pp. 115-119. 
Mundial. La seguridad no fue el único vínculo, lo fue también la relación económica, para lo cual ambos actores se transformaron en los principales socios económicos. Asimismo, compartieron lazos culturales y étnicos con valores comunes enraizados en los principios y valores de la Ilustración. Por su parte, la Organización del Atlántico Norte (OTAN) estructuró y formalizó estos lazos de alianza política.

\section{Estados Unidos acentuó el unilateralismo ante la amenaza del uso de armas de destrucción masiva.}

- No obstante lo anterior, incluso durante la Guerra Fría, la alianza experimentó algunos cambios. Por ejemplo, en el plano económico, el comercio intrahemisférico declinó en relación con el actual intercambio comercial de Estados Unidos con Asia, que supera en $50 \%$ el que mantiene con la Alianza Atlántica.

- Del mismo modo, con el colapso de la Unión Soviética y la transformación del sistema internacional, el proceso europeo entró en otra fase de expansión e integración autonómica. El establecimiento de la Unión Monetaria Europea y la coordinación política más estrecha bajo el Tratado de Maastricht, en 1992, condujo a una política exterior y de seguridad común entre los socios europeos.

- Las consecuencias que ha acarreado la actual política exterior estadounidense de considerar que el contraterrorismo es el principio ordenador de su estrategia de seguridad nacional, también ha causa- do tensiones en la agenda internacional, al señalar el presidente Bush en su mensaje al Congreso norteamericano después del 11 de septiembre que la relación de Estados Unidos con otros países sería juzgada conforme a si "están con nosotros o contra nosotros" en la guerra contra el terrorismo. Esto atrajo a Rusia y China a la esfera de los aliados estadounidenses.

- Apoyo irrestricto a Ariel Sharon en el Medio Oriente contra la insurrección palestina y distanciamiento de sus socios tradicionales árabes, como Arabia Saudita.

- El peligro del uso de armas de destrucción masiva por parte del terrorismo internacional lleva a Bush a acentuar el unilateralismo.

- A pesar de sus propias aprehensiones respecto de las consecuencias negativas de la globalización y del terrorismo en particular Europa, tiene aproximaciones diferentes a las manifestadas por Estados Unidos. Se apoya más en la cooperación como imperativo histórico y en los mecanismos multilaterales, de manera que no concuerda con la conducta unilateral del primero en cuanto al rechazo estadounidense del Protocolo de Kyoto sobre el cambio climático, a la no aprobación de la Corte Internacional Penal, del Tratado sobre las minas terrestres, y dell protocolo sobre las armas biológicas, entre otros.

- La divergencia más de fondo se traduce en una percepción de que los Estados Unidos están abordando el tema del terrorismo transnacional principalmente como estrategia militar y no desde la perspectiva política, diplomática y económica.

- Este pesimismo se contrapone a dos razones: primero, en la era de la globaliza- 
ción, la mayoría de los estadounidenses reconocen que aun con la gran capacidad militar y el dominio económico de su país, los objetivos nacionales clave no pueden sostenerse sin la ayuda de otros. En segundo lugar, la mayoría de los europeos entienden y aceptan que el imperio del derecho y las instituciones internacionales son insuficientes para enfrentar los desafíos globales y, a pesar de la fortaleza creciente de la UE, siguen considerando a los Estados Unidos como socio, y valorándolo como tal.

- Pese a las tensiones actuales, la confluencia de estas dos aproximaciones provee una base fresca para lograr una nueva relación transatlántica, entendiendo con ello los principales temas económicos y políticos del mundo de hoy ${ }^{15}$.

\section{ESFERAS DE COOPERACIÓN}

EN LA RELACIÓN TRANSATLÁNTICA

Estados Unidos y Europa están vinculados dinámicamente en una asociación estratégica que genera roces y encuentros. Lo importante para preservar de esta alianza es evitar que aumenten las diferencias hasta llegar a un divorcio entre las partes. Se trata, entonces, de relaciones que al comenzar el siglo XXI atraviesan por un cambio estructural. Instituciones creadas y desarrolladas en un determinado contexto histórico deben adaptarse ahora a otro distinto y más incierto.

\section{Para preservar la alianza hay que evitar que las diferencias conduzcan al divorcio entre las partes.}

En el plano de la seguridad y la defensa, tanto objetiva como subjetivamente, hay fuertes razones para pensar que los desafíos que enfrentan tanto Estados Unidos como Europa son más compartidos que divergentes. Aceptando las diferencias en materia de capacidad militar entre ambos lados del Atlántico, un paso en la dirección correcta es el concepto de tareas conjuntas dentro de la OTAN que permita formar coaliciones y fuerzas voluntarias sin que necesariamente deban participar de todas las partes. Asimismo, el desarrollo de una política exterior y de seguridad común europea es funcional como elemento interlocutor de Estados Unidos en Europa, en especial cuando deba involucrarse en alguna acción diplomática con el viejo continente.

Por su parte, en áreas regionales como los Balcanes, es importante que sean las fuerzas europeas las que lideren los esfuerzos de pacificación y reconstrucción. Esto significa que los Estados Unidos conservarán su interés y prestarán y ayuda en esta tarea, pero las diferencias en cuanto al grado de interés nacional involucrado hacen menos probable mayores divergencias. Esta política supone también seguir cooperando en zonas como el Cercano Oriente, donde el cuarteto integrado por 
Estados Unidos, las Naciones Unidas, la Unión Europea y Rusia ha asumido un papel importante, y la Unión Europea no es excluida, como en el pasado.

\section{La superpotencia es un objetivo más atractivo para los terroristas.}

Desde el punto de vista de la amenaza global, el caso más dramático es el del terrorismo. El peligro que representan organizaciones como Al Qaeda para Europa no es idéntico al que enfrenta Estados Unidos. Este país, que se proclama y es considerado ampliamente como campeón de los valores occidentales, al mismo tiempo que se le reconoce como única superpotencia con presencia más determinante en el mundo árabe $\mathrm{e}$ islámico, es un objetivo más atractivo para los terroristas. No obstante, los atentados ocurridos en otras latitudes, en particular el sufrido por la población de Madrid en marzo de 2004 y cuya autoría ha sido reclamada por los líderes de $\mathrm{Al}$ Qaeda, demuestran claramente que Europa y otras democracias occidentales también están amenazadas. En consecuencia, la respuesta a este flagelo transnacional hace necesaria la cooperación transatlántica, tal como ha ocurrido en Afganistán.

El aspecto económico, particularmente en el campo monetario, es importante que tanto Estados Unidos como Europa y también Japón inserten sus relaciones financieras en un contexto global. El problema es la relación entre el euro, el dólar y el yen. Las relaciones monetarias entre los tres serán importantes para mantener la competencia entre estas monedas dentro de límites manejables.

En el área del comercio, Estados Unidos y Europa no pueden permitir que las disputas se les escapen de las manos. Más allá de los acuerdos específicos que han logrado ambas partes, como el sistema de advertencia logrado en 1999, también lo es que ambos traten de usar la Organización Mundial de Comercio y sus mecanismos de solución de controversias como manera de despolitizar algunos de los desacuerdos que puedan surgir. Ambas partes pueden contribuir a mejorar las estructuras e instituciones del régimen internacional de comercio mediante la aplicación de las reglas de la OMC.

Otra área de acomodo o ajuste entre Estados Unidos y Europa es aquella de la consulta política. Particularmente importantes son en esta materia las instancias de negociación y la búsqueda de consensos políticos. La habilidad de comunicarse oportuna y eficazmente antes de abordar los temas de negociación ayuda a identificar las fuentes de fricción y la intensidad de las preferencias y contribuye a facilitar los compromisos. Para alcanzar estos objetivos, las reuniones y encuentros entre ministros y altos personeros de gobierno son de gran utilidad. Sin embargo, las dos reuniones anuales de representantes de Estados Unidos y la UE no son suficientes para estos propósitos. En otras palabras, desarrollando nuevos mecanismos informales de consulta, podrán evitarse algunos de los engorrosos aspectos de los procedimien- 
tos entre ambos actores internacionales ${ }^{16}$.

En el ámbito de la sociedad civil, es muy determinante la colaboración conjunta en cuestiones transnacionales, desde el terrorismo hasta los temas de la libertad religiosa, pasando por el narcotráfico y las epidemias o enfermedades infecciosas de distinta naturaleza. Asimismo, es gravitante la cooperación en el plano de los movimientos de capitales, el flujo de bienes y servicios, los problemas ambientales y de migraciones, en particular el tráfico de seres humanos. Estos desafíos transna-cionales requieren respuestas transna-cionales y colaboración en el plano bilateral y multilateral, ya que no existen respuestas nacionales a los problemas de alcance y dimensiones globales ${ }^{17}$.

\section{UNIDAD Y DIVERSIDAD:} REVALORACIÓN DE LA COOPERACIÓN Y ACCIÓN MULTILATERAL

El contraste entre Estados Unidos y Europa como actores y sistemas de gobiemo es fuente de confusión respecto de sus roles en la política mundial en los tres escenarios globales de Nye, ya analizados. Es difícil explicar, entonces, las consecuencias de que coexistan, por un parte un sistema federal y centralizado a un lado del Atlántico y una serie de gobiernos coordinados, por la otra ${ }^{18}$.

\section{Estados Unidos evoluciona cada vez} más hacia una integración de su identidad nacional.

No obstante los lazos crecientes de interdependencia económica, cultural y política dentro de la comunidad atlántica, la mayor que puedan tener los Estados Unidos en el contexto de su proyección internacional, existen diferencias dentro de esta unidad. La distinción fundamental es que Estados Unidos evoluciona cada vez más hacia una estrecha integración de su identidad nacional. A pesar de su diversidad cultural y de su condición de sociedad multiétnica, ella es cada vez más patriótica y profundamente estadounidense. Las consecuencias de los acontecimientos del 11 de Septiembre de 2001. han reforzado estas tendencias. Por su parte, la Unión Europea está experimentando un resurgimiento del interés en preservar su diversidad nacional en el contexto de los procesos de integración e identidad continental. Además, la diversidad que se persigue en Europa está profundamente enraizada en su reacción a la inseguridad económica

16 Acerca de estas fuentes de fricción y cooperación en las relaciones transatlánticas, véase Nye Jr., Joseph S., "The US and Europe: Continental Drift?", en Inlermational Affairs, Vol. 76, $N^{\circ}$ 1, January 2000, pp. 56-57.

17 Haass, Richard, "Las relaciones trasatlánticas en el nuevo orden de seguridad", op. cil., p. 42.

18 Jones, Eric, "Debating the trasallantic relationship: thetoric and reality", en Intemational Affairs, Vol. $80, N^{\circ} 4$, July 2004, p. 609. 
de occidente y en el reciente éxito frente duradera. La crisis de inseguridad global a la dominación comunista en el este. ${ }^{19}$

El problema es que a los distintos europeos les resulta relativamente fácil tener una relación individual con los Estados Unidos. Del mismo modo, a los estadounidenses les cuesta entender o apreciar la diversidad de Europa. No obstante estas diferencias de apreciación, la relación transatlántica es mucho más profunda y generada en el período post- septiembre 11, unida a los acontecimientos en Irak abren nuevas expectativas para revalorar la flexibilidad y la cooperación y retomar con nuevos bríos la acción multilateral a ambos lados del Atlántico. Las actuales tendencias de la comunidad atlántica, manifestadas en declaraciones y conductas específicas, así lo están demostrando.

19 Jones, Eric, ibid., pp. 609-610. 